\title{
Geoscience, sustainability and ethical investing
}

To ensure finance and investment institutions create sustainable policies, geoscientists must have a seat at the table, argues Matthew Pannett

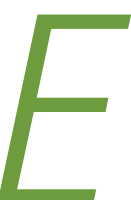

nvironmental, social and governance (ESG) regulations are currently the number one topic for finance and investment institutions in the UK and continental Europe, and geoscientists have an important role to play in this agenda. The need for sustainable finance is largely being driven by a generation of people who are increasingly making investment decisions from pensions to purchases - based on ethical considerations.

\section{EU regulations and net zero}

The link between geoscience and finance and investment is not immediately obvious, but dig a little deeper and the role of the geoscientist becomes clearer.

Recently, political agreement was reached on the EU's sustainable investment disclosure rules that will require companies to disclose, amongst other things, investment impacts on the environment. The EU is also examining how to integrate sustainability considerations into its financial policy framework in order to mobilise finance for sustainable growth while reducing pressures on the environment. These regulations are designed to support the EU's aspirations of a lowcarbon, more resource-efficient and sustainable economy. Mark Carney, the outgoing governor of the Bank of England, has also spoken about the need for action to achieve net zero emissions and the potential failure of industries, sectors and firms that lag behind or do not adapt. The UK hosting the United Nations Climate Change Conference (COP26) later in 2020 and aspirations to be net zero by 2050 will only increase the focus on climate change and decarbonisation.

To be credible, ESG and sustainability need to be clearly defined, with standards and a common language. Geoscientists have a deep understanding of Earth processes, including carbon cycles, water, resources and life on land, and can provide the necessary 'translation' of the Earth sciences into this language of sustainability. Consideration of sustainability criteria, such as benchmarking against the UN Sustainable Development Goals, or more specific metrics, such as carbon accounting, should now form part of our decision-making processes, whether it be resource extraction, re-use of aggregates, protection of soil or sustainable remediation.

\section{Global economics}

ESG will become increasingly important in global economics with central banks 'stress testing' climate change impacts on investment decisions. Emerging risks, which could include water and other resource scarcity, or changes in the behaviour of pollutants in the environment, are factors that will create stresses on economies. Clear understanding of these types of risks are needed to develop climate change resilience, an increasingly necessary measure to protect assets, investments and businesses.

Such decisions on sustainability cannot be made in isolation and all stakeholders need to be involved to create ESG and sustainable policies, and avoid 'greenwashing'.

Geoscientists need a seat at the table and the ability to engage in this evolving arena where Earth and social sciences blend with economics and ethics.

Recent surveys show that climate change is the number one risk to business, and we need to be ready for this challenge. Now is the time for the geoscience community to become conversant in the language of sustainability.

Matthew Pannett (CGeol) is a Principal at Ramboll's London office

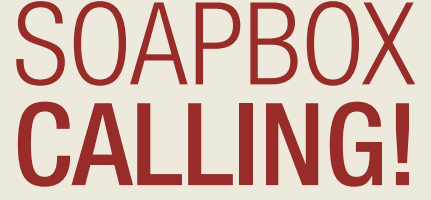

Soapbox is open to contributions from all Fellows. You can always write a letter to the Editor, of course, but perhaps you feel you need more space?

If you can write it entertainingly in 500 words, the Editor would like to hear from you. Email your piece, and a self-portrait, to

sarah.day@geolsoc.org.uk. Copy can only be accepted electronically. No diagrams, tables or other illustrations please.

Pictures should be of print quality - please take photographs on the largest setting on your camera, with a plain background.

Precedence will always be given to more topical contributions.

Any one contributor may not appear more often than once per volume (once every 12 months).

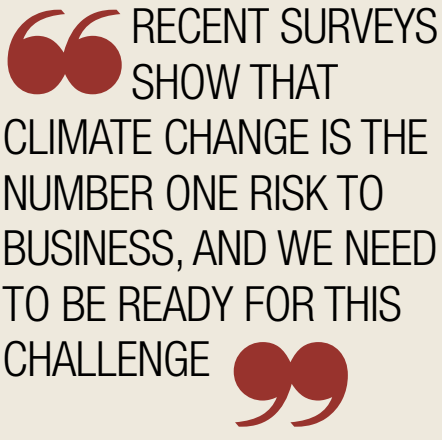

MATTHEW PANNETT 